\title{
Temperature Effects of Low Noise InGaP/InGaAs/GaAs PHEMTs
}

\author{
H. K. Huang, C. S. Wang and Y. H. Wang* \\ Department of Electrical Engineering, \\ National Cheng-Kung University \\ Tainan, Taiwan, R.O.C.; \\ *E-mail:YHW@eembox.ncku.edu.tw
}

\author{
C. L. Wu and C. S. Chang \\ Transcom, Inc. Tainan, Taiwan, R.O.C.
}

\begin{abstract}
The temperature-dependent DC characteristics and noise performance of $\operatorname{In}_{0.49} G a_{0.51} P / \operatorname{In}_{0.15} G a_{0.85} A s / G a A s$ low noise pseudomorphic high electron mobility transistors (PHEMTs) with the gate dimensions of 0.25 $\times 160 \mu^{2}$ were investigated at $12 \mathrm{GHz}$ with temperature ranging from $300 \mathrm{~K}$ to $450 \mathrm{~K}$. It is found that the variation of the turn-on voltage for drain-to-gate Schottky diode was $-1.05 \mathrm{mV} / \mathrm{K}$ and reverse voltages, at a fixed 0.5 $\mathrm{mA} / \mathrm{mm}$ of gate current, was $-6 \mathrm{mV} / \mathrm{K}$. The temperaturedependence of pinch-off voltage was $-1.01 \mathrm{mV} / \mathrm{K}$ and leakage current was $0.043 \mu \mathrm{A} / \mathrm{K}$. Comparisons of noise performance including minimum noise figure and associated gain between $\operatorname{In}_{0.49} G a_{0.51} P / \operatorname{In}_{0.15} G a_{0.85} A s$ and $A l_{0.25} G a_{0.75} A s / I n_{0.15} G a_{0.85} A s$ low noise PHEMTs were also made. It is found that the high temperature performance of $\mathrm{In}_{0.49} \mathrm{Ga} a_{0.51} \mathrm{P} / \mathrm{In}_{0.15} \mathrm{Ga} a_{0.85} \mathrm{As}$ PHEMT is much better than that of $A l_{0.25} G a_{0.75} A s / I n_{0.15} G a_{0.85} A s$ due to the less effects of deep level traps by absence of DX-center and lower leakage current by higher Schottky barrier and valence band discontinuity.
\end{abstract}

\section{Introduction}

The low noise devices play very important roles in wireless systems. As we know, the InP-based HEMT's show the best noise performance [1], but it is very difficult for their fabrication processes as compared to those of GaAs-based HEMT's. This encourages the development of GaAs-based low-noise AlGaAs/InGaAs/ GaAs pseudomorphic HEMT's in these applications [2]. However, several disadvantages still exist, for example, in the viewpoint of achieving precise control of gate recess etching and reliability for thermal stress.

As compared to AlGaAs gated PHEMTs, InGaPrelated devices with the following advantages: higher InGaP energy gap, higher valence band discontinuity [3], no deep-complex (DX) center [4], excellent etching selectivity between InGaP and GaAs [5][6], and good thermal stability, are developed recently [6]. As mentioned above, InGaP-based devices are the better choice than AlGaAs-based [7] in low noise applications, such as low noise MMIC. To mention noise performance of low noise devices, thermal effects are one of the most important issues to result in the degradation of low noise device performance. Therefore, the development of thermal-related reliability in InGaP-based devices is the furthest and most important issues.

Recently, super low noise InGaP gated PHEMT devices have been demonstrated with $0.46 \mathrm{~dB}$ minimum noise figure and $13 \mathrm{~dB}$ associated gain at $12 \mathrm{GHz}$, with the gate dimension of $0.25 \times 160 \mu \mathrm{m}^{2}$ [7]. However, the temperature-dependent of InGaP PHEMTs device parameter and noise performance are still limited. In this paper, we will discuss the temperature effects on InGaP low noise devices for DC characteristics and noise performance. Furthermore, the noise performance between InGaP and $\mathrm{AlGaAs}$ low noise devices in different temperatures ranging from $300 \mathrm{~K}$ to $450 \mathrm{~K}$ will be also compared. Due to better temperature-dependent noise performance, InGaP/InGaAs/GaAs low noise PHEMT is more promising for low noise applications.

\section{Experimental}

$\mathrm{In}_{0.49} \mathrm{Ga}_{0.51} \mathrm{P} / \mathrm{In}_{0.15} \mathrm{Ga}_{0.85} \mathrm{As} / \mathrm{GaAs}$ low noise PHEMTs, as shown in figure 1 , were grown by metal-organic chemical vapor deposition (MOCVD) with composed of an $\mathrm{GaAs} / \mathrm{Al}_{0.25} \mathrm{Ga}_{0.75} \mathrm{As} / \mathrm{GaAs}$ buffer layer, an undoped $\mathrm{In}_{0.15} \mathrm{Ga}_{0.85} \mathrm{As}$ channel layer, an undoped $\mathrm{In}_{0.49} \mathrm{Ga}_{0.51} \mathrm{P}$ spacer layer, n-type $\mathrm{In}_{0.49} \mathrm{Ga}_{0.51} \mathrm{P}$ donor layer, an undoped $\mathrm{In}_{0.49} \mathrm{Ga}_{0.51} \mathrm{P}$ Schottky layer, and a heavily-doped n-type GaAs cap layer. These layers were grown on (100)oriented semi-insulating 4-inch GaAs substrate. The active part of the structure was a $145 \AA$ undoped $\mathrm{In}_{0.15} \mathrm{Ga}_{0.51} \mathrm{As}$ channel. The Hall mobilities at room temperature and $77 \mathrm{~K}$ are $5170 \mathrm{~cm}^{2} / \mathrm{V}$.sec and 18700 $\mathrm{cm}^{2} / \mathrm{V}$.sec, corresponding to the two-dimensional carrier densities $2.14 \times 10^{12} \mathrm{~cm}^{-2}$ and $1.98 \times 10^{12} \mathrm{~cm}^{-2}$, respectively.

Devices were processed by conventional optical lithography technique. There are three major steps in this super low noise InGaP gated PHEMT fabrication: device isolation, ohmic contact, and Schottky contact. The etching of InGaP for the mesa was achieved using an $\mathrm{HCl} / \mathrm{H}_{3} \mathrm{PO}_{4}$ (3:1) solution. The $\mathrm{Au} / \mathrm{Ge} / \mathrm{Ni}$ was evaporated to form the source and drain ohmic contacts by a 20-s $420^{\circ} \mathrm{C}$ hot plate anneal. To form the InGaP gate, the 
$\mathrm{HF} / \mathrm{H}_{2} \mathrm{O}_{2} / \mathrm{H}_{2} \mathrm{O}$ solution was used for selectively removing the cap GaAs material. The Ti/Pt/Au was then deposited for the Schottky gate by lift-off. The gate dimension of the devices was $0.25 \mu \mathrm{m} \times 160 \mu \mathrm{m}$.

\begin{tabular}{|c|c|c|}
\hline Source & & Drain \\
\hline \multicolumn{3}{|c|}{ n-In $0.4 \mathrm{Ga}_{0.51} \mathbf{P}$} \\
\hline \multicolumn{3}{|c|}{ n-In ${ }_{0.4} G_{a_{0.51}} \mathbf{P}$} \\
\hline \multicolumn{3}{|c|}{ n-In $0.4 \mathrm{Ga}_{0.51} \mathbf{P}$} \\
\hline \multicolumn{3}{|c|}{ i-In 0.15 Ga ass As } \\
\hline \multicolumn{3}{|c|}{ i-GaAs } \\
\hline \multicolumn{3}{|c|}{ i-Al ${ }_{0.25}$ Ga $a \pi \mathrm{As}$} \\
\hline \multicolumn{3}{|c|}{ i-G aAs } \\
\hline
\end{tabular}

Figure1. Cross-sectional view of $\operatorname{In}_{0.49} \mathrm{Ga}_{0.51} \mathrm{P} / \mathrm{In}_{0.15}$ $\mathrm{Ga}_{0.85} \mathrm{As} / \mathrm{G}$ aAs low noise PHEMT structure.

We have measured the DC characteristics at different temperatures ranging from $300 \mathrm{~K}$ to $450 \mathrm{~K}$, including 1) Schottky diode characteristics, 2) pinch-off voltage shift, 3) current-voltage characteristics, 4) the increment of gate leakage current following temperature increments and 5) thermal performance in noise exhibition. We have also measured the thermal performance in noise performance of AlGaAs PHEMT for comparison.

\section{Temperature-dependent characteristics}

As shown in figure 2, the temperature-dependent characteristics of the Schottky diode were measured. In forward bias, as revealed in the inset of figure 2 , the turn-on voltage defined at forward current of 0.5 $\mathrm{mA} / \mathrm{mm}$ were 0.675 and $0.52 \mathrm{~V}$ at temperature of $\mathrm{T}=$ $300 \mathrm{~K}$ and $450 \mathrm{~K}$, respectively. The temperaturedependent variational ratio of turn-on voltage was -1.05 $\mathrm{mV} / \mathrm{K}$. On the other side, the temperature-dependent characteristics of reverse currents were also examined. The reverse current increases with increasing operation temperature. Respectively, the reverse voltages measured at $80 \mu \mathrm{A}$ are 9.1 and $8.2 \mathrm{~V}$ at $300 \mathrm{~K}$ and $450 \mathrm{~K}$ and the temperature-dependent variational ratio of reverse voltages was $-6 \mathrm{mV} / \mathrm{K}$. Due to the $1.92 \mathrm{eV}$ of bandgap of the InGaP to be a Schottky layer in PHEMT devices, the reliable $\Delta \mathrm{E}_{\mathrm{V}}$ at $\mathrm{In}_{0.49} \mathrm{Ga}_{0.51} \mathrm{P} / \mathrm{In}_{0.15} \mathrm{Ga}_{0.85}$ As is to be 0.377 $\mathrm{eV}$ [3]. Such a high $\Delta \mathrm{E}_{\mathrm{V}}$ can prevent the holes generated by thermal effects and impact ionization to pass into the gate to be leakage current, and the higher Schottky barrier of InGaP, is same reasons for reducing leakage current when devices are in operation. As mentioned above, we can find such small temperaturedependent Schottky diode characteristics of $-1.05 \mathrm{mV} / \mathrm{K}$ in forward bias and $-6 \mathrm{mV} / \mathrm{K}$ in reverse bias.

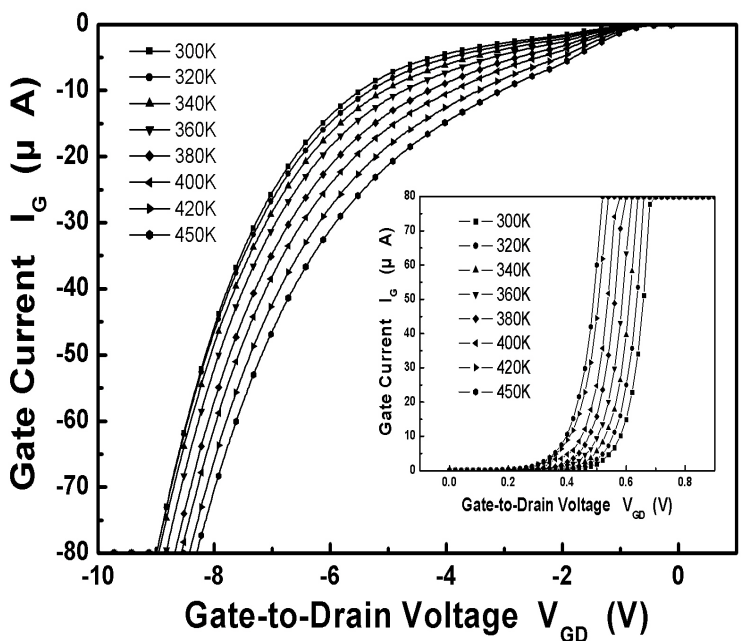

Figure2. The reverse-bias characteristics of gate-todrain Schottky diode : Inset is for forward-bias.

The temperature-dependent characteristics of pinchoff voltages, as shown in figure 3 , were measured at $\mathrm{V}_{\mathrm{DS}}$ $=2 \mathrm{~V}$ and $\mathrm{I}_{\mathrm{DS}}=2 \mathrm{~mA} / \mathrm{mm}$ under the devices' operation. The temperature-dependent variational ratio of pinch-off voltage was $-1.01 \mathrm{mV} / \mathrm{K}$

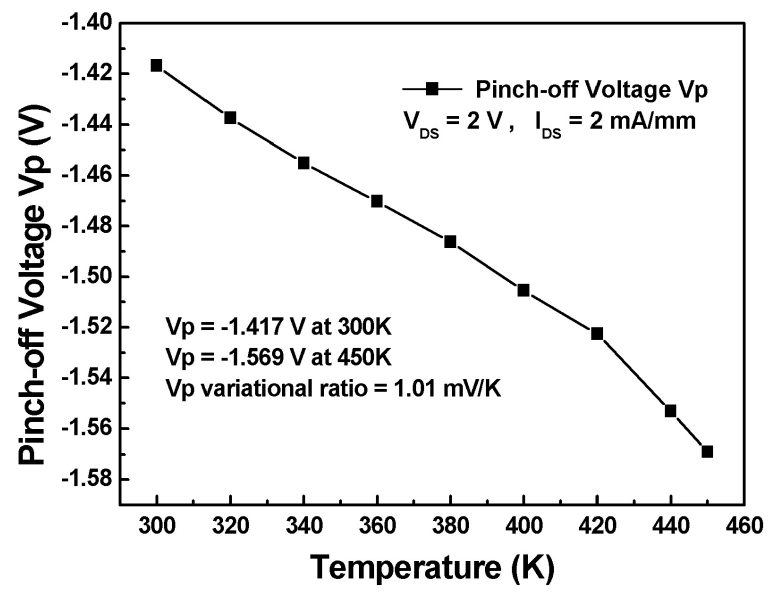

Figure 3. Temperature-dependent characteristics of pinch-off voltage: Measure at $\mathrm{V}_{\mathrm{DS}}=2 \mathrm{~V}$ and $\mathrm{I}_{\mathrm{DS}}=2$ $\mathrm{mA} / \mathrm{mm}$.

We measured minimum noise figure at $12 \mathrm{GHz}$, which $\mathrm{DC}$ bias is $\mathrm{V}_{\mathrm{DS}}=2 \mathrm{~V}$ and $\mathrm{I}_{\mathrm{DS}}=10 \mathrm{~mA}$. The $\mathrm{V}_{\mathrm{GS}}$ with $\mathrm{I}_{\mathrm{DS}}$ $=10 \mathrm{~mA}$ is near $-0.75 \mathrm{~V}$, as shown in figure 4 . Hence the temperature-dependent variational ratio of leakage current with $\mathrm{V}_{\mathrm{GS}}=-0.75 \mathrm{~V}$ was a significant factor to evaluate thermal effects of noise performance.

As shown in figure 5, the temperature-dependent variational ratio of leakage current was $0.043 \mu \mathrm{A} / \mathrm{K}$ at $\mathrm{V}_{\mathrm{GS}}=-0.75 \mathrm{~V}$. The temperature-dependent characteristics of reverse gate-to-drain voltage $\left(\mathrm{V}_{\mathrm{GD}}\right)$ and gateleakage current $\left(\mathrm{I}_{\mathrm{G}}\right)$, with fixed $-0.5 \mathrm{~mA} / \mathrm{mm}$ of gate current and $-9 \mathrm{~V}$ of gate-to-drain voltage, were measured as shown in figure 6 and related variations were 0.258 $\mu \mathrm{A} / \mathrm{K}$ of $\mathrm{I}_{\mathrm{G}}$ and $-6 \mathrm{mV} / \mathrm{K}$ of $\mathrm{V}_{\mathrm{DG}}$, respectively. 


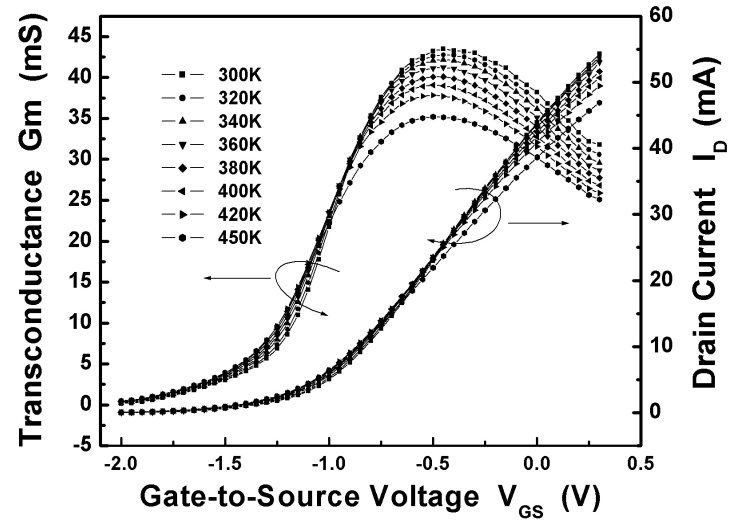

Figure 4. Temperature-dependent transfer curves of low noise InGaP PHEMTs : Measured at VDS = $2 \mathrm{~V}$.

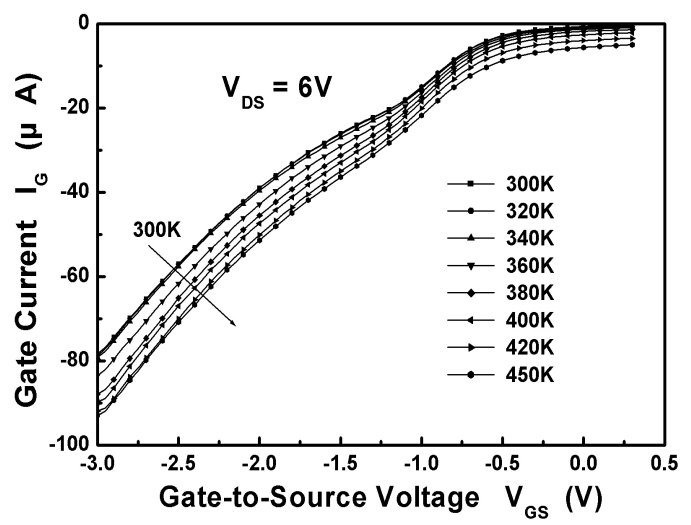

Figure 5. Temperature-dependent characteristics of gate current $\mathrm{I}_{\mathrm{G}}$ with temperature ranging from $300 \mathrm{~K}$ to $450 \mathrm{~K}$ at $\mathrm{V}_{D S}=6 \mathrm{~V}$.

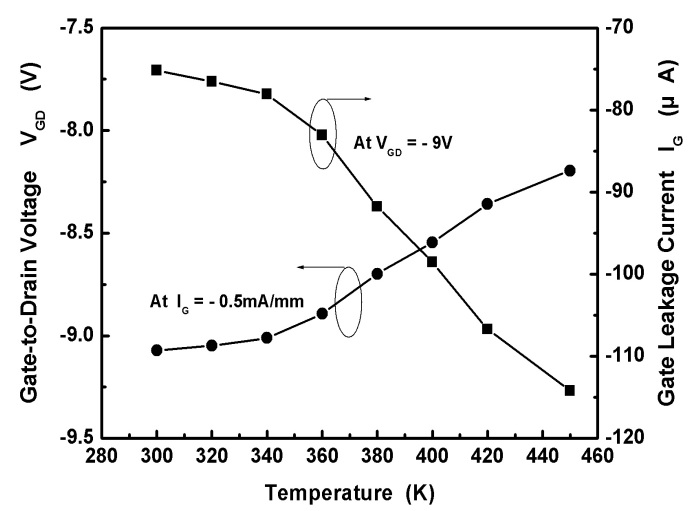

Figure 6. Temperature-dependent characteristics of reverse gate-to-drain voltage $\left(\mathrm{V}_{\mathrm{GD}}\right)$ and gateleakage current $\left(I_{G}\right)$ at a fixed $-0.5 \mathrm{~mA} / \mathrm{mm}$ of gate current and - $9 \mathrm{~V}$ of gate-to-drain voltage, respectively.

The current-voltage characteristics were measured as shown in figure 7. A significant drop in high drain current is essentially due to the decreased channel mobilities caused by phonon scattering and a significant degradation of the Schottky diode performance [8]. On the other hand, a slight increment in low drain current is primarily due to pinch-off voltage shifts towards further negative $V_{G S}$ values caused by thermal effect. The curve of $\mathrm{V}_{\mathrm{GS}}=-0.6 \mathrm{~V}$ was with two phenomena, one is a slight increment of drain current at from $\mathrm{V}_{\mathrm{DS}}=0 \mathrm{~V}$ to $3.5 \mathrm{~V}$ and the other is a significant drop of drain current at $\mathrm{V}_{\mathrm{DS}}$ $>3.5 \mathrm{~V}$.

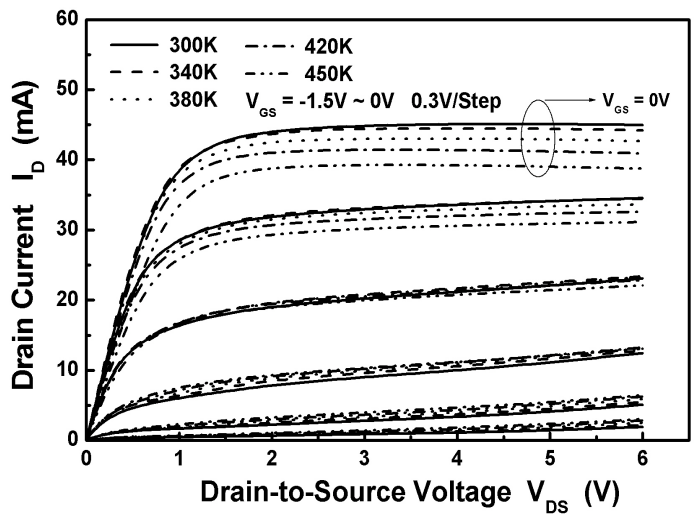

Figure 7. Temperature-dependent current-voltage characteristics of low noise InGaP PHEMTs.

\section{Noise performance}

The noise performance of low-noise InGaP gated PHEMTs were better than AlGaAs [7]. The minimum noise figure $\left(\mathrm{NF}_{\min }\right)$ and associated gain $\left(\mathrm{G}_{\mathrm{a}}\right)$ of $\mathrm{InGaP}$ and $\mathrm{AlGaAs}$ were measured at $12 \mathrm{GHz}$, which DC bias is $V_{D S}=2 \mathrm{~V}$ and $I_{D S}=10 \mathrm{~mA}$, with different temperature ranging from $300 \mathrm{~K}$ to $450 \mathrm{~K}$. The $\mathrm{NF}_{\text {min }}$ and $\mathrm{G}_{\mathrm{a}}$ of $\mathrm{InGaP}$ and $\mathrm{AlGaAs}$ at $300 \mathrm{~K}$ and $450 \mathrm{~K}$ were shown in Table 1. The temperature-dependent $\mathrm{NF}_{\text {min }}$ and $\mathrm{G}_{\mathrm{a}}$ was be normalized by the $\mathrm{NF}_{\min }$ and $\mathrm{G}_{\mathrm{a}}$ at $300 \mathrm{~K}$, as shown in figure 8. Both kinds of PHEMTs - InGaP and AlGaAs are conventional single heterojunction PHEMTs with gate dimensions are $0.25 \times 160 \mu \mathrm{m}^{2}$. Furthermore, we examined the reliability of temperature-dependent noise performance between InGaP and $\mathrm{AlGaAs}$. We found temperature-dependent variations of $\mathrm{NF}_{\min }$ and $\mathrm{G}_{\mathrm{a}}$ of AlGaAs was much higher than InGaP when measured temperature was increased slightly from $300 \mathrm{~K}$ to $320 \mathrm{~K}$, i.e. the increment was $20 \mathrm{~K}$. This means $\mathrm{AlGaAs}$ PHEMT is more sensitive to temperature. The noise performance of InGaP PHEMTS, at temperatures ranging from $300 \mathrm{~K}$ to $450 \mathrm{~K}$, was all better than that of AlGaAs.

Table $1 . N F_{\min }$ and $G_{a}$ of InGaP and AIGaAs at $300 \mathrm{~K}$ and $450 \mathrm{~K}$, at $12 \mathrm{GHz}$.

\begin{tabular}{|c|c|c|c|c|}
\hline & \multicolumn{2}{|c|}{ InGaP } & \multicolumn{2}{c|}{ AlGaAs } \\
\hline & $300 \mathrm{~K}$ & $450 \mathrm{~K}$ & $300 \mathrm{~K}$ & $450 \mathrm{~K}$ \\
\hline $\mathrm{NF}_{\text {min }}(\mathrm{dB})$ & 0.46 & 1.76 & 0.53 & 1.88 \\
\hline $\mathrm{G}_{\mathrm{a}}(\mathrm{dB})$ & 13 & 10.63 & 12.87 & 10.33 \\
\hline
\end{tabular}




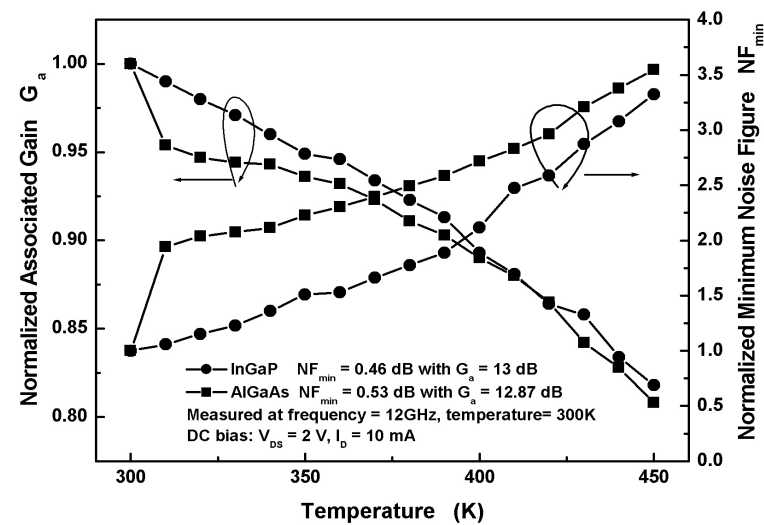

Figure 8. The temperature-dependent performance of normalized minimum noise figure and associated gain at $12 \mathrm{GHz}$. Both gate dimensions of $\operatorname{lnG} \mathrm{aP}$ and AlGaAs are $0.25 \times 160 \mu \mathrm{m}^{2}$

\section{Conclusion}

In summary, experimental results of temperaturedependent DC characteristics, minimum noise figure and associated gain of low noise InGaP PHEMTs have been demonstrated. Comparison of the noise performance between InGaP and AlGaAs PHEMT has also been made. Small variations of DC characteristics of temperature effects on InGaP devices, as mention above, are observed due to the advantages of InGaP essential attribution. Subsequently, the temperature-dependent noise performance of low noise InGaP PHEMT is proved better than that of AlGaAs.

Hence, the InGaP/InGaAs/GaAs low noise PHEMTs are not only having better noise performance than AlGaAs, but also having higher stability of temperaturedependent characteristics. As the results show, InGaP $/$ InGaAs/GaAs PHEMTs are promising for low noise MMIC applications which require excellent good thermal stability.

\section{Acknowledgment}

The work was supported in part by the National Science Council under the contract NSC90-2215-E-006013.

\section{References}

[1] P. C. Chao, A. J. Tessmer, K.-H. G. Duh, P. Ho, M.-Y. Kao, P. M. Smith, J. M. Ballingall, S.-M. J. Liu and A. A. Jabra, "W-band low-noise InAlAs/ InGaAs lattice-matched HEMTs", IEEE Electron Device Lett., vol. 11, no. 1, Jan. 1990, pp.59-62

[2] K. L. Tan, R. M. Dia, D. C. Streit, A. C. Han, T. Q. Trinh, J. R. Velebir, P. H. Liu, T. Lin, H. C. Yen, M. Sholley and L. Shaw, "Ultralow-noise W-band pseudomorphic InGaAs HEMT's" IEEE Electron Device Lett., vol. 11, no. 11, Nov. 1990, pp. 303-305

[3] M. A. Rao, E. J. Caine, H. Kroemer, S. I. Long and D. I. Babic "Determination of valence and conduction-band discontinuities at the $(\mathrm{Ga}$, In) $\mathrm{P} / \mathrm{GaAs}$ heterojunction by $\mathrm{C}-\mathrm{V}$ profiling", J. Appl. Phys., vol. 61, No. 2, Feb. 1986, pp. 643-649

[4] Y. J. Chan and D. Pavlidis, "Trap studies in GaInP/GaAs and AlGaAs/GaAs HEMT's by means of low-frequency noise and transconductance dispersion characterizations" IEEE Trans. Electron Devices, vol. 41, no. 5, May 1994, pp. 637-642

[5] Y. Okamoto, K. Matsunaga, M. Kuzuhara and M. Kanamori, "Novel InGaP/AlGaAs/InGaAs heterojunction FET for X-Ku band power applications", IEEE MTT-S Dig., vol. 3, 1997, pp. $1191-1194$

[6] S. Fujita, T. Noda, A. Wagai, C. Nozaki and Y. Ashizawa, "Novel HEMT Structures Using a Strained InGaP Schottky Layer" in Proc. 5th Int. Conf. Indium Phosphide and Related Materials, Paris, France. Apr. 1993, pp. 497 -500

[7] H. K. Huang, Y. H. Wang, C. L. Wu, J. C. Wang and C. S. Chang, "Super Low Noise InGaP Gated PHEMT", IEEE Electron Device Lett., vol. 23, no. 2, Feb. 2002, pp.70-72

[8] F. S. Shoucair and P. K. Ojala, "High-temperature electrical characteristics of GaAs MESFET's $\left(25-400^{\circ} \mathrm{C}\right)$ ", IEEE Trans. Electron Devices, vol. 39, no. 7, Jul. 1992, pp. $1551-1557$ 